\title{
The complex relationship between bone remodeling and the physical and material properties of bone
}

\author{
D. B. Burr
}

Received: 6 November 2014 / Accepted: 16 November 2014/Published online: 20 December 2014

(C) International Osteoporosis Foundation and National Osteoporosis Foundation 2014

Bone's fracture resistance is dependent on the amount of bone, its architectural organization, and the material properties of the matrix that compose it. Although past concentration has been on mass and geometry, there is increasing recognition that bone's material properties play a critical role in its fracture resistance. Unlike bone mass which is determined by one feature-how much? - or architecture, which is determined by two features - amount and location-material properties are determined by a dynamic complex and multi-level set of molecular components and processes that are interdependent. This includes the materials themselves - collagen, mineral, noncollagenous proteins, and water-how they are assembled, and the nature of the interfaces between them. These properties of the material are, in turn, partly dependent on the rate of bone turnover. As turnover decreases, bone's mean tissue age becomes older, causing the collagen to become more highly cross-linked, the mineral to accumulate and contribute to increasing homogeneity, and the tissue to become less hydrated (only partly because mineral displaces some of the water). During aging, each of these features contributes to decrease the ductility of the bone, which in turn contributes to the skeletal fragility caused by bone loss and measured by BMD.

The recent paper in Osteoporosis International by Ural et al. [1] examines age-dependent and age-independent correlations among several parameters of cortical bone measured

\section{B. Burr $(\bowtie)$}

Department of Anatomy and Cell Biology, Indiana University School of Medicine, 635 Barnhill Dr, Indianapolis, IN 46202, USA

e-mail: dburr@iupui.edu

D. B. Burr

Department of Biomedical Engineering, Indiana University-Purdue University Indianapolis (IUPUI), Indianapolis, IN, USA from the same donors and that define bone quality at the tissue level. The paper shows the effects that age-related changes in bone remodeling parameters have on properties of the tissue that help to define bone quality. The paper shows that fewer sites of resorption and smaller resorption pits are associated with more areas of diffuse microdamage, but no relationship to linear microcrack density, independent of age.

These relationships are all shown through correlation analysis, which doesn't define causation and may reflect different effects stemming from a single cause. For example, the data show that the resorption pit density (a surrogate for activation frequency) and area of diffuse damage in bone are inversely related, yet recent evidence suggests that diffuse damage does not target itself for repair like linear microcracks do. Herman et al. [2] first showed that although areas associated with linear microcracks cause osteocyte apoptosis and increase activation of new remodeling units, those areas of bone that contain only diffuse damage have neither elevated osteocyte apoptosis nor altered activation and repair. This year, Seref-Felenguez et al. [3] presented the first quantitative data to show that diffuse damage can be repaired directly in vivo, without the intervening step of bone remodeling. They observed that the area of diffuse damage created by acute creep loading in rats was significantly reduced 14 days following the load, without any evidence of the activation of new intracortical resorption sites. Thus, the inverse association between diffuse damage and resorption found in the paper by Ural is probably incidental. Interestingly, Ural et al. found no age-independent association between linear microcrack density and resorption parameters even though it is well established now that the two are linked through the process of targeted remodeling [4, 5].

Accumulation of advanced glycation end-products (AGEs) in cortical bone occurs naturally with age [6], and may contribute to age-related skeletal fragility. AGEs form intrafibrillar collagen crosslink-like bonds and stiffen the collagen fiber matrix. They are the result of a series of 
posttranslational modifications that occur through the process of non-enzymatic glycation. In diabetic conditions, they occur when reducing sugars spontaneously condense free amino groups such as lysine and arginine, but also can form as a consequence of spontaneous and naturally occurring oxidation reactions. Interestingly, the role played by AGEs themselves and the interaction with their receptor, RAGE, on bone resorption parameters has been less well investigated. The accumulation of AGEs can increase RAGE expression [7], which in turn can affect both bone formation and bone resorption. On the bone formation side, RAGE expression has been found to inhibit osteoblast differentiation [7] and accelerate apoptosis [8]. However, they also can stimulate osteoclast differentiation and activation through the RANKL pathway [9]. Thus, an accumulation of AGEs in bone tissue might be expected to contribute to an increased bone resorption and impaired refilling of the erosion spaces. Ural's study, however, in showing an inverse relationship between AGEs and resorption density, does not suggest that this is a component of agerelated skeletal fragility.

Nevertheless, AGEs are well known to have a significant negative age-related effect on bone's material properties by reducing toughness (the energy required to initiate or propagate a crack) because it makes bone tissue more brittle [10-12]. This is likely to be one reason that people with Type 2 diabetes who have normal bone mass nevertheless have an increased risk for fracture. Indeed, although historically the mantra was that osteoporosis was a condition of too little bone but one in which the bone tissue was not compromised, it is recognized now that at least a portion of the increasing skeletal fragility that occurs in both men and women is related to alteration in the tissue matrix itself, independent of how much of it one has, or how it is organized at the macrostructural level. Surprisingly, although the increased brittleness caused by AGE accumulation would suggest that there should be a relationship to increased microcrack initiation [13], Ural et al. found no association between crack accumulation and AGE accumulation. This relationship between AGE accumulation and microcrack formation has been shown experimentally in vitro, but other correlational studies of human bone also failed to demonstrate a relationship between the two $[14,15]$. The reasons for the failure to find a relationship are unclear, especially as Ural et al. show age-related increases in both AGE accumulation and crack density.

The mechanical properties of bone can be significantly influenced by the number, size, and location of resorption cavities [16]. Their effect can be related to the initial porosity $[16,17]$ and to the strain distribution. Ural et al. show that the average number and size of erosion sites in cortical bone declines significantly with age. This is contrary to much evidence on age-related changes in bone extending back at least 50 years when Jowsey [18] showed an increase in erosion perimeter near the endocortical surface of the femur in both men and women over the age of 60 years. She did not refine this observation to determine whether this was due to more or larger erosions. Closer to the periosteal surface, the number of erosion cavities may remain more constant, although reduced osteoblast vigor and a prolonged formation period in osteoporotic individuals leads to greater cortical porosity in the tibia [19]. However, the balance between erosion number and erosion size is itself dependent on age and possibly on gender. The activation rate for cortical remodeling doubles between the 4 th and 7 th decades, but decreases significantly in both men and women in their 80s and 90s [20, 21]. It also is a well-known fact that osteon size (which after all is a remnant of a former erosion space) decreases with age [20], even though Haversian canal size may increase, probably as a function of the deterioration of the individual activity of both osteoclasts and osteoblasts in older individuals. Thompson [22] suggested that increased cortical porosity with age is caused by increased Haversian canal size in women, but more canals and smaller osteons (i.e., smaller erosion cavity sizes) in men. Thus, Ural et al.'s observations can be rationalized with these earlier studies if one considers both the gender distribution and age distribution of the sample. The sample included three times more males than females, suggesting that the data may be weighted to smaller erosions, and included individuals in the very old age groups, in which the number and rate of erosions has slowed [21]. Thus, even though the cortical remodeling rate may increase in middle age, including individuals in the 9th and 10th decades of life may leverage the regression to reflect the reduced remodeling that occurs in the very old age groups. A linear regression may even obscure the variations that occur in remodeling rate in younger and middle-aged adults. Even so, it also should be recognized that the three-dimensional characteristics of resorption cavities cannot always be determined from two dimensional histological analyses. In two-dimensional space, fewer cavities cannot be differentiated from more cavities (increased activation of new resorption spaces) that are smaller $[5,16]$.

There is a second important effect of these erosion patterns on the cortical matrix of bone. The reduced number and size of erosion spaces will be inextricably linked to an increase in the interstitial matrix. The mean tissue age of this interstitial matrix is older than that within newly created osteonal bone. It is interesting in that regard, and entirely plausible, that this will be associated with an increase in crack density, both as a function of a higher rate of crack initiation in these older, more highly mineralized interstitial regions $[23,24]$ and because of the reduced rate of repair. Besides increasing the area of the interstitial matrix where cracks tend to initiate, fewer and smaller erosions could result in a shorter cumulative osteonal cement line perimeter, reducing further the energy absorbing capacity of bone matrix by impairing its ability to slow crack growth. This would lead to significantly shorter fatigue life of bone under cyclic loading, as was recently shown to occur 
when bone remodeling is suppressed artificially using antiresorptive medications [25].

These combined effects - increased AGE accumulation leading to a more brittle matrix, increased interstitial matrix associated with greater accumulation of damage, and a limitation of the ability to arrest cracks associated with changes in osteonal morphology - may interact to contribute to that component of age-related skeletal fragility that is independent of changes in bone mineral density alone [26-28].

\section{Grant Support None}

Disclosures None

\section{References}

1. Ural A, Janeiro C, Karim L, Diab T, D1 V (2015) Association between non-enzymatic glycation, resorption, and microdamage in human tibial cortices. Osteoporos Int. doi:10.1007/s00198-0142938-4

2. Herman BC, Cardoso L, Majeska RJ, Jepsen KJ, Schaffler MB (2010) Activation of bone remodeling after fatigue: Differential response to linear microcracks and diffuse damage. Bone 47:766772

3. Seref-Ferlenguez Z, Basta-Pijakic J, Kennedy OD, Philemon CJ, Schaffler MB (2014) Structural and mechanical repair of diffuse damage in cortical bone in vivo. J Bone Miner Res. doi:10.1002/ jbmr2309

4. Burr DB (2002) Targeted and nontargeted remodeling. Bone 30:2-4

5. Parfitt AM (2002) Targeted and nontargeted remodeling: Relationship to basic multicellular unit origination and progression. Bone 30:5-7

6. Odetti P, Rossi S, Monacelli F, Poggi A, Cirnigliaro M, Federici M, Federici A (2005) Advanced glycation end products and bone loss during aging. Ann NY Acad Sci 1043:710-717

7. Okazaki K, Yamaguchi T, Tanaka K-I, Notsu M, Ogawa N, Yano S, Sugimoto T (2012) Advanced glycation end products (AGEs), but not high glucose, inhibit osteoblastic differentiation of mouse stromal ST2 cells. Calcif Tiss Int 91:286-296

8. Alikhani M, Alikhani Z, Boyd C, MacLellan CM, Raptis M, Liu R et al (2007) Advanced glycation end products stimulate osteoblast apoptosis via the MAP kinase and cytosolic apoptotic pathways. Bone 40:345-353

9. Zhou Z, Han JY, Xi CX, Xie JX, Feng X, Wang CY et al (2008) HMGB1 regulates RANKL-induced osteoclastogenesis in a manner dependent on RAGE. J Bone Miner Res 23:1084-1096
10. Saito M, Marumo K (2010) Collagen cross-links as a determinant of bone quality: a possible explanation for bone fragility in aging, osteoporosis, and diabetes mellitus. Osteoporos Int 21:195-214

11. Tang SY, Allen MR, Phipps R, Burr DB, Vashishth D (2009) Changes in non-enzymatic glycation and its association with altered mechanical properties following 1-year treatment with risedronate or alendronate. Osteoporos Int 20:887-894

12. Zioupos P, Wang XT, Currey JD (1996) The accumulation of fatigue microdamage in human cortical bone of two different ages in vitro. Clin Biomech 11:365-375

13. Tang SY, Vashishth D (2010) Non-enzymatic glycation alters microdamage formation in human cancellous bone. Bone 46:148154

14. Follet H, Viguet-Carrin S, Burt-Pichat B, Dépalle BY, Gineyts E et al (2011) Effects of preexisting microdamage, collagen cross-links, degree of mineralization age, and architecture on compressive mechanical properties of elderly human vertebral trabecular bone. $\mathrm{J}$ Orthop Res 29:481-488

15. Follet H, Farlay D, Bala Y, Viguet-Carrin S, Gineyts E, Burt-Pichat B et al (2013) Determinants of microdamage in elderly human vertebral trabecular bone. PLoS ONE 8:355232

16. Hernandez CJ (2008) How can bone turnover modify bone strength independent of bone mass? Bone 42:1014-1020

17. Schaffler MB, Burr DB (1988) Stiffness of compact bone: Effects of porosity and density. J Biomech 21:13-16

18. Jowsey J (1960) Age changes in human bone. Clin Orthop Rel Res $17: 210-217$

19. Ortner DJ (1975) Aging effects on osteon remodeling. Calcif Tiss Res 18:27-36

20. Martin RB, Burr DB (1989) Structure, function and adaptation of compact bone. Raven Press, New York, ch. 8

21. Simmons ED Jr, Pritzker KPH, Grynpas MD (1991) Age-related changes in the human femoral cortex. J Orthop Res 9:155-167

22. Thompson DD (1980) Age changes in bone mineralization, cortical thickness and Haversian canal area. Calcif Tiss Int 31:5-11

23. Schaffler MB, Choi K, Milgrom C (1995) Aging and bone matrix microdamage accumulation in human compact bone. Bone 17:521525

24. Norman TL, Wang Z (1997) Microdamage of human cortical bone: Incidence and morphology in long bones. Bone 20:375-379

25. Bajaj D, Geissler JR, Allen MR, Burr DB, Fritton JC (2014) The resistance of cortical bone tissue to failure under cyclic loading is reduced with alendronate. Bone 64:57-64

26. Hui SL, Slemenda CW, Johnston CC Jr (1988) Age and bone mass as predictors of fracture in a prospective study. J Clin Invest 81:1804 1809

27. De Laet CEDH, van Hout BA, Burger H, Hofman A, Pols HAP (1997) Bone density and risk of hip fracture in men and women: Cross-sectional analysis. Br Med J 315:221-225

28. Kanis JA, Johnell O, Oden A, Dawson A, De Laet C, Jonsson B (2001) Ten year probabilities of osteoporotic fractures according to BMD and diagnostic thresholds. Osteoporos Int 12:989-995 